\title{
Improvements in patient-reported outcomes with apremilast, an oral phosphodiesterase 4 inhibitor, in the treatment of moderate to severe psoriasis: results from a phase Ilb randomized, controlled study
}

Vibeke Strand ${ }^{1 *}$, David Fiorentino ${ }^{2}$, ChiaChi Hu${ }^{3}$, Robert M Day ${ }^{3}$, Randall M Stevens ${ }^{3}$ and Kim A Papp ${ }^{4}$

\begin{abstract}
Background: Apremilast, a specific inhibitor of phosphodiesterase 4, modulates pro-inflammatory and antiinflammatory cytokine production.
\end{abstract}

Objectives: Apremilast's effect on patient-reported outcomes (PROs) in patients with moderate to severe psoriasis was evaluated in a phase Illb randomized, controlled trial (NCT00773734).

Methods: In this 16-week, placebo-controlled study, 352 patients with moderate to severe plaque psoriasis received placebo or apremilast (10, 20, or $30 \mathrm{mg}$ BID). PROs included Dermatology Life Quality Index (DLQI), pruritus visual analog scale (VAS), and Short-Form Health Survey (SF-36) to assess health-related quality of life (HRQOL). Changes from baseline and patients reporting improvements $\geq$ minimum clinically important differences (MCID) were analyzed. Correlations between changes across various PRO instruments were explored.

Results: Baseline DLQI (>10 points) and SF-36 MCS and domain scores indicated impairments in HRQOL. At 16 weeks, greater improvements from baseline in DLQI scores were reported with apremilast $20(-5.9)$ and $30 \mathrm{mg}$ BID (-4.4) compared with placebo (1.9; $P \leq 0.005$ for both), and a greater proportion of patients reported improvements $\geq$ MCID (20 mg BID, 49.4\%, 30 mg BID, 44.3\%) versus placebo (25.0\%; $P<0.04)$. Greater improvements from baseline in pruritus VAS scores were reported with apremilast $20(-35.5 \%)$ and $30 \mathrm{mg}$ BID (-43.7\%) versus placebo $(-6.1 \% ; P \leq 0.005)$. Significant and clinically meaningful improvements in SF-36 mental component summary scores $(P \leq 0.008)$ and Bodily Pain, Mental Health, and Role-Emotional domains were reported with all apremilast doses $(P<0.05)$, and Social Functioning with 20 and $30 \mathrm{mg} \mathrm{BID}(P<0.05)$ and Physical Functioning with $20 \mathrm{mg}$ BID $(P<0.03)$. Correlations between SF-36 scores and DLQI were moderate $(r>0.30$ and $\leq 0.60)$ and low between SF-36 and pruritus VAS $(r \leq 0.30)$, indicating they measure different aspects of the disease.

Conclusions: Apremilast treatment resulted in improved HRQOL, including DLQI and pruritus VAS over 16 weeks of treatment, in patients with moderate to severe psoriasis.

Keywords: Apremilast, Dermatology Life Quality Index, Phosphodiesterase 4, Psoriasis, Quality of life, SF-36

\footnotetext{
* Correspondence: vstrand@stanford.edu

'Division of Immunology and Rheumatology, Stanford University, Palo Alto, California, USA

Full list of author information is available at the end of the article
} 


\section{Background}

Psoriasis is a chronic inflammatory disease that affects approximately $1 \%$ to $3 \%$ of the worldwide population $[1,2]$. Individuals with psoriasis report impaired healthrelated quality of life (HRQOL), ranging from physical discomfort and limitations in activities of daily living to psychosocial problems and emotional distress [3-7]. Furthermore, the severity of psoriasis symptoms, and pruritus in particular, has been linked to the degree of HRQOL impairment $[3,4]$.

Many therapies for psoriasis treatment improve HRQOL [8-10]. Despite this, each therapy's benefit can be compromised by poor tolerability, adverse events, and route of administration (particularly injection/infusion reactions) [11,12]. These limitations underscore the persistent unmet need for additional treatment options for psoriasis [13]. As new therapies become available for managing psoriasis, it is important to evaluate their impact on patient-reported HRQOL.

Research over the past decade in inflammatory diseases such as psoriasis has focused upon modulation of cyclic adenosine monophosphate (cAMP), a naturally occurring intracellular secondary messenger that maintains immune homeostasis by modulating production of pro-inflammatory and anti-inflammatory cytokines $[14,15]$. Phosphodiesterase 4 (PDE4) is a cAMP-specific PDE and the dominant PDE in inflammatory cells. PDE4 inhibition elevates intracellular cAMP, which in turn down-regulates the inflammatory response [16-19]. Apremilast (CC-10004; Celgene Corporation, Summit, NJ, USA) is a small molecule that specifically inhibits PDE4, thereby elevating intracellular cAMP levels. Elevated intracellular cAMP reduces pro-inflammatory mediators, such as tumor necrosis factor- $\alpha$, interleukin- 23 , and interferon- $\gamma$, and increases production of anti-inflammatory mediators, such as interleukin-10 [18]. Clinical studies have demonstrated the efficacy and tolerability of apremilast in moderate to severe psoriasis and psoriatic arthritis (PsA) [20-22].

In this phase IIb, multicenter, randomized, controlled trial (RCT), orally administered apremilast (10 mg BID, $20 \mathrm{mg}$ BID, or $30 \mathrm{mg}$ BID) resulted in dose-dependent efficacy for the treatment of moderate to severe plaque psoriasis [20]. A significantly greater proportion of patients receiving apremilast $20 \mathrm{mg}(28.7 \%)$ and $30 \mathrm{mg}$ BID (40.9\%) achieved $\geq 75 \%$ mean reductions from baseline in Psoriasis Area and Severity Index (PASI-75) scores compared with placebo $(P<0.001)$ after 16 weeks of treatment [20]. Reductions in baseline PASI scores were evident by week 2 , with a separation across doses observed by weeks 2 to 4 ; improvements were maintained over 24 weeks' treatment. Significant improvements in pruritus visual analog scale (VAS), static Physician's Global Assessment, and body surface area
(BSA) scores were also reported. It is hypothesized that clinical improvements would be accompanied by improvements in patient-assessed HRQOL. This report summarizes the impact of apremilast on patient-reported outcomes (PROs) over the initial 16-week placebocontrolled treatment phase of this trial.

\section{Materials and methods Study design}

This phase IIb RCT was conducted at 35 sites in the United States and Canada between September 2008 and November 2009. Methods, including enrollment, study design, and procedures, have been previously published [20]. Briefly, men and women $\geq 18$ years of age with stable, chronic, moderate to severe plaque psoriasis (PASI $\geq 12$ and BSA $\geq 10 \%$ for $\geq 6$ months) who were candidates for phototherapy or systemic therapy were enrolled and randomized 1:1:1:1 to receive apremilast 10, 20 , or $30 \mathrm{mg}$ BID or placebo for 16 weeks. At week 16, placebo patients were re-randomized 1:1 to apremilast 20 or $30 \mathrm{mg}$ BID until week 24 in blinded fashion; all other patients continued their assigned dose of apremilast. Throughout the trial, concomitant phototherapy and use of systemic and biologic agents were prohibited. Use of topical agents was also prohibited, with the exception of Eucerin ${ }^{\circ}$ cream for body lesions; low-potency corticosteroids for facial, axillary, and groin psoriasis lesions; and coal tar shampoo or salicylic acid preparations for scalp lesions. All patients provided written informed consent before study-related procedures were done, and the protocol and consent were approved by institutional review boards or ethics committees at all investigational sites.

\section{PRO assessments}

Changes from baseline to week 16 and improvements $\geq$ minimum clinically important differences (MCID) were determined for PROs, including the Dermatology Life Quality Index (DLQI), pruritus VAS scores, and ShortForm Health Survey version 2 (SF-36) (Table 1). The DLQI is a 10-item questionnaire that assesses the impact of skin disease on HRQOL over the previous week. Scores for each item range from 0 (not at all affected) to 3 (very much affected); total scores range from 0 to 30 and those $>10$ represent a very large impact on HRQOL [28]. The pruritus VAS assesses severity of psoriasisrelated pruritus over the past 24 hours, on a 0 - to 100 $\mathrm{mm}$ scale ( $0=$ no itch, $100=$ worst itch imaginable). SF- 36 is a generic HRQOL questionnaire with 36 questions combined into 8 domains, scored from 0 (worst) to 100 (best). Domain scores are combined into physical (PCS) and mental component summary (MCS) scores with normative scores of 50 and standard deviations (SDs) of 10. 
Table 1 Overview of HRQOL assessment instruments and MCID [23-27]

\begin{tabular}{|c|c|c|c|}
\hline Instrument & Description & Scale & MCID \\
\hline \multirow[t]{2}{*}{ Pruritus VAS } & - Pruritus visual analog scale & 0-100 mm, including "anchors" & 10.0 points \\
\hline & & (best to worst) & \\
\hline \multirow[t]{8}{*}{ DLQI } & - Dermatology Life Quality Index & 0-30 points & 5.0 points \\
\hline & - Subject report, 10 questions addressing: & (best to worst) & \\
\hline & - Symptoms & & \\
\hline & - Feelings & & \\
\hline & - Daily activities & & \\
\hline & - Leisure & & \\
\hline & - Work & & \\
\hline & - Personal relationships & & \\
\hline \multirow[t]{9}{*}{ SF-36 domains* } & - Patient report, 36 items & $0-100 \mathrm{~mm}$ & 5.0 points \\
\hline & - Physical Functioning & (worst to best) & \\
\hline & - Role-Physical & & \\
\hline & - Bodily Pain & & \\
\hline & - General Health & & \\
\hline & - Vitality & & \\
\hline & - Role-Emotional & & \\
\hline & - Social Functioning & & \\
\hline & - Mental Health & & \\
\hline SF-36 PCS and MCS scores & - Calculated based upon domain scores & Normative value: mean $=50, S D=10$ & 2.5 points \\
\hline
\end{tabular}

*Based on transformed scale scores.

HRQOL, health-related quality of life; MCID, minimum clinically important differences; MCS, mental component summary; PCS, physical component summary; SF-36, 36-Item Short-Form Health Survey version 2.

\section{End points and statistical analysis}

PROs were evaluated based on the intent-to-treat population using last-observation-carried-forward (LOCF) to account for missing values. Week 16 changes from baseline in DLQI and SF-36 scores were examined using ANCOVA, with treatment as a factor and baseline as a covariate. Week 16 percent change from baseline in mean pruritus VAS scores was compared using the Wilcoxon test for each apremilast group versus placebo. If either PCS and/or MCS scores of SF-36 were statistically significant, significance was tested for the individual domain scores, without $P$ value corrections for multiplicity. Mean changes from baseline in domain scores are displayed using spydergrams [29], with quantification of improvements using the health utility SF-6D measure, after the method of Ara and Brazier [30,31]. As a benchmark comparison, US normative data were calculated based on age and gender distribution of the protocol population [32]. Pearson correlations (r) were determined for mean changes from baseline between the generic SF-36 Bodily Pain (BP) and Vitality (VT) domains and MCS scores at week 16 with disease-specific DLQI and pruritus VAS scores. Correlations $>0.30$ to $\leq 0.60$ were considered moderate and $>0.60$ high [33]. These were unplanned, post hoc analyses based on results from secondary analysis of PROs, with the $P$ values presented for inferential use.

\section{Results}

Patients

The majority of patients $(\mathrm{N}=352)$ were men $(62.8 \%)$, white $(92.9 \%)$, and obese (mean \pm SD body mass index, $\left.31.2 \pm 7.1 \mathrm{~kg} / \mathrm{m}^{2}\right)$. Patients had plaque psoriasis for a mean of 19 years and $21 \%$ had PsA (Table 2).

\section{PRO assessments}

DLQI

Mean DLQI scores were similar and $>10$ across all treatment groups at baseline (Table 3). At week 16, mean DLQI scores were significantly lower (vs. placebo) with apremilast $20 \mathrm{mg}$ BID $(P<0.001)$ and $30 \mathrm{mg}$ BID $(P=0.005)$, but not with $10 \mathrm{mg}$ BID $(P=0.132)$. Twentytwo (25.0\%) placebo, $30(33.7 \%)$ apremilast $10 \mathrm{mg}$ BID $(P=0.249), 43$ (49.4\%) $20 \mathrm{mg}$ BID ( $P=0.001$ vs. placebo), and 39 (44.3\%) $30 \mathrm{mg}$ BID ( $P=0.011$ vs. placebo) patients reported improvements $\geq$ MCID.

\section{Pruritus VAS}

Baseline pruritus VAS scores were well matched across treatment groups (Table 3). Significantly greater reductions 
Table 2 Baseline demographic and clinical characteristics of the enrolled population

\begin{tabular}{|c|c|c|c|c|c|}
\hline \multirow[t]{2}{*}{ Characteristic } & \multirow[t]{2}{*}{ Placebo $(n=88)$} & \multicolumn{3}{|c|}{ Apremilast BID } & \multirow[t]{2}{*}{ Total $(\mathrm{N}=352)$} \\
\hline & & $10 \mathrm{mg}(\mathrm{n}=89)$ & $20 \mathrm{mg}(\mathrm{n}=87)$ & $30 \mathrm{mg}(\mathrm{n}=88)$ & \\
\hline Age (years) & $44.1 \pm 13.7$ & $44.4 \pm 14.0$ & $44.6 \pm 12.6$ & $44.1 \pm 14.7$ & $44.3 \pm 13.7$ \\
\hline Male & $53(60.2)$ & $63(70.8)$ & $55(63.2)$ & $50(56.8)$ & $221(62.8)$ \\
\hline \multicolumn{6}{|l|}{ Race } \\
\hline White & $83(94.3)$ & $82(92.1)$ & $82(94.3)$ & $80(90.9)$ & $327(92.9)$ \\
\hline Black & $1(1.1)$ & $2(2.2)$ & $1(1.1)$ & $2(2.3)$ & $6(1.7)$ \\
\hline Asian & $4(4.5)$ & $3(3.4)$ & $2(2.3)$ & $4(4.5)$ & $13(3.7)$ \\
\hline Other & $0(0.0)$ & $2(2.2)$ & $2(2.3)$ & $2(2.3)$ & $6(1.7)$ \\
\hline Height (cm) & $171.2 \pm 8.6$ & $171.5 \pm 10.2$ & $171.7 \pm 9.6$ & $171.2 \pm 10.7$ & $171.5 \pm 9.6$ \\
\hline Weight (kg) & $90.3 \pm 21.4$ & $95.7 \pm 23.2$ & $89.9 \pm 20.2$ & $91.2 \pm 23.1$ & $91.8 \pm 22.0$ \\
\hline $\mathrm{BMI}\left(\mathrm{kg} / \mathrm{m}^{2}\right)$ & $30.8 \pm 6.7$ & $32.5 \pm 7.4$ & $30.4 \pm 6.2$ & $31.1 \pm 7.8$ & $31.2 \pm 7.1$ \\
\hline Total PASI score & $18.1 \pm 5.7$ & $18.1 \pm 6.3$ & $18.5 \pm 7.3$ & $19.1 \pm 7.1$ & $18.5 \pm 6.6$ \\
\hline BSA & $21.0 \pm 11.2$ & $21.3 \pm 11.4$ & $20.7 \pm 12.4$ & $25.0 \pm 15.4$ & $22.0 \pm 12.8$ \\
\hline + History PsA & $17(19.3)$ & $20(22.5)$ & $16(18.4)$ & $21(23.9)$ & $74(21.0)$ \\
\hline Plaque psoriasis history (years) & $19.6 \pm 11.6$ & $18.0 \pm 12.4$ & $19.2 \pm 12.2$ & $19.2 \pm 12.0$ & $19.0 \pm 12.0$ \\
\hline Previous systemic therapy for psoriasis & $39(44.3)$ & $47(52.8)$ & $43(49.4)$ & $47(53.4)$ & $176(50.0)$ \\
\hline
\end{tabular}

Values are mean \pm SD or $\mathrm{n}(\%)$. BMI, body mass index; BSA, body surface area; PASI, Psoriasis Area and Severity Index; PsA, psoriatic arthritis.

from baseline in mean pruritus scores at week 16 were reported with apremilast $20 \mathrm{mg} B \mathrm{BD}(P=0.005)$ and $30 \mathrm{mg}$ BID $(P<0.001)$, but not with $10 \mathrm{mg} \operatorname{BID}(P=0.366)$ versus placebo. Thirty-nine (44.3\%) placebo, 47 (52.8\%) apremilast $10 \mathrm{mg}$ BID ( $P=0.294), 53(60.9 \%) 20 \mathrm{mg}$ BID ( $P=0.034$ vs. placebo), and $56(63.6 \%) 30 \mathrm{mg}$ BID patients $(P=0.015)$ reported improvements $\geq$ MCID.

\section{SF-36 MCS and PCS scores}

At baseline, mean SF-36 MCS scores across treatment groups were 0.5 SDs lower than US normative scores of 50 (range: 45.7-47.0), whereas SF-36 PCS scores approximated 50 (range 48.6-49.3). After 16 weeks of treatment, mean changes from baseline in MCS scores were significantly greater with apremilast 10,20 , or $30 \mathrm{mg}$ BID than placebo (Figure 1), exceeding MCID, and approaching US normative values (range: 49.0-49.9). Week 16 mean changes from baseline in PCS scores were numerically greater with apremilast 10,20 , and 30 $\mathrm{mg}$ BID than placebo but were neither statistically significantly nor clinically meaningful.

\section{SF-36 domain scores}

At baseline, SF-36 domain scores were generally well matched between study groups and equaled or were within 10 points of age- and gender-matched normative scores. At week 16, no significant changes from baseline in any domain were evident in the placebo group.

In patients receiving apremilast $10 \mathrm{mg}$ BID, mean changes from baseline were statistically significant and $\geq$ MCID in three of eight domains: BP, Mental Health $(\mathrm{MH}$ ), and Role-Emotional (RE; $P=0.007$ for all; Figure 2).

Table 3 Summary DLQI and pruritus VAS scores at week 16

\begin{tabular}{|c|c|c|c|c|}
\hline \multirow[t]{2}{*}{ Patient-reported outcome } & \multirow[t]{2}{*}{ Placebo $(n=88)$} & \multicolumn{3}{|c|}{ Apremilast BID } \\
\hline & & $10 \mathrm{mg}(\mathrm{n}=89)$ & $20 \mathrm{mg}(\mathrm{n}=86)$ & $30 \mathrm{mg}(\mathrm{n}=88)$ \\
\hline \multicolumn{5}{|l|}{ DLQI } \\
\hline Baseline & $10.7 \pm 6.7$ & $10.8 \pm 6.3$ & $11.6 \pm 7.0$ & $10.6 \pm 6.2$ \\
\hline Week 16 & $8.6 \pm 7.6$ & $7.6 \pm 6.3$ & $5.8 \pm 6.0$ & $6.0 \pm 6.2$ \\
\hline Change from baseline & $-1.9 \pm 5.2$ & $-3.2 \pm 6.0$ & $-5.9 \pm 6.7^{*}$ & $-4.4 \pm 5.1^{*}$ \\
\hline \multicolumn{5}{|l|}{ Pruritus VAS } \\
\hline Baseline & $55.5 \pm 25.5$ & $54.1 \pm 23.5$ & $58.3 \pm 26.7$ & $55.3 \pm 25.5$ \\
\hline Week 16 & $45.6 \pm 30.2$ & $39.0 \pm 27.8$ & $35.2 \pm 29.2$ & $31.6 \pm 30.0$ \\
\hline Percent change from baseline & $-6.1 \pm 76.4$ & $-10.2 \pm 100.8$ & $-35.5 \pm 66.0^{*}$ & $-43.7 \pm 46.8^{*}$ \\
\hline
\end{tabular}




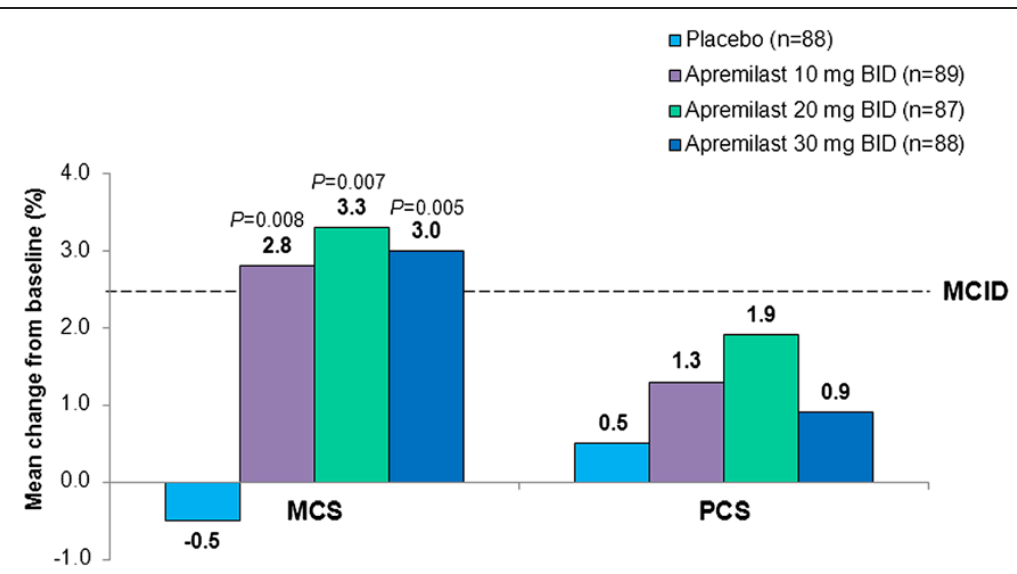

Figure 1 Mean change from baseline in SF-36 physical and mental component summary scores at week 16. $P$ values (Vs. placebo), based on ANCOVA, with treatment as the factor, and baseline value as the covariate. An increase in score indicates improvement. MCID, minimal clinically important difference; SF-36, 36-item Short-Form Health Survey.

In the apremilast $20 \mathrm{mg}$ BID group, mean changes from baseline were statistically significant in five domains (Physical Functioning [PF; $P=0.028]$, BP $[P=0.025]$, Social Functioning [SF; $P=0.046]$, RE $[P=0.004]$, and $\mathrm{MH}$ $[P=0.012]$ ), and $\geq \mathrm{MCID}$ in six domains (PF, BP, SF, RE, $\mathrm{MH}$, and RP) (Figure 3). Improvements reported in the apremilast $30 \mathrm{mg}$ BID group were statistically significant in four domains: BP $(P=0.023)$, SF $(P=0.028), \quad \mathrm{RE}$ $(P=0.006)$, and $\mathrm{MH}(P=0.013)$ and $\geq \mathrm{MCID}$ in three (BP, $\mathrm{SF}$, and RE) (Figure 4). Across all three active doses, statistically significant improvements were reported in BP, $\mathrm{MH}$, and RE, and in SF for apremilast 20 and $30 \mathrm{mg}$ BID, contributing to statistically significant changes in MCS scores. Mean changes from baseline in SF-6D scores were 0.042 and 0.052 , respectively, in the apremilast 10 and $20 \mathrm{mg}$ BID dose groups, exceeding minimum important differences (MID), and 0.036, approaching MID, with $30 \mathrm{mg}$ BID.

\section{Correlations among DLQI, pruritus VAS, and SF-36 scores}

Correlations observed between generic SF-36 MCS, BP, and VT domain scores and disease-specific DLQI and pruritus VAS scores were analyzed (Table 4). With all doses of apremilast, statistically significant moderate correlations were observed between SF-36 BP domain and DLQI $(P<0.001)$ and MCS scores and DLQI $(P<0.001)$. Correlations between SF-36 VT domain and DLQI were overall low, but statistically significant with apremilast $20 \mathrm{mg}(P=0.003)$ and $30 \mathrm{mg}$ BID $(P=0.040)$. Correlations between BP domain and pruritus VAS were

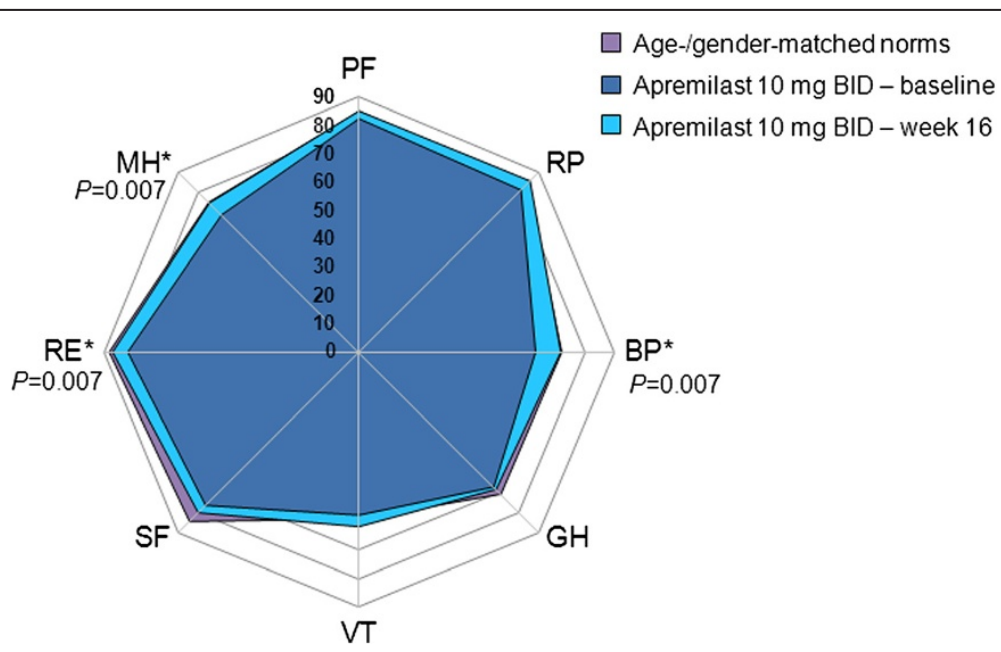

Figure 2 SF-36 domain scores at baseline and week 16 with apremilast 10 mg BID. Spydergram of SF-36 domain scores in patients receiving apremilast $10 \mathrm{mg}$ BID versus US age-/gender-matched norms (lavender) and baseline (dark blue). Gridlines represent changes of 10 points each (10 points $=2 \times$ MCID). An increase in score indicates improvement. Treatment-associated improvements (light blue) are statistically significant and $\geq M C I D$ in three of eight domains. MCID, minimal clinically important difference; SF-36, 36-item Short-Form Health Survey. ${ }^{*} \geq \mathrm{MCID}$. 


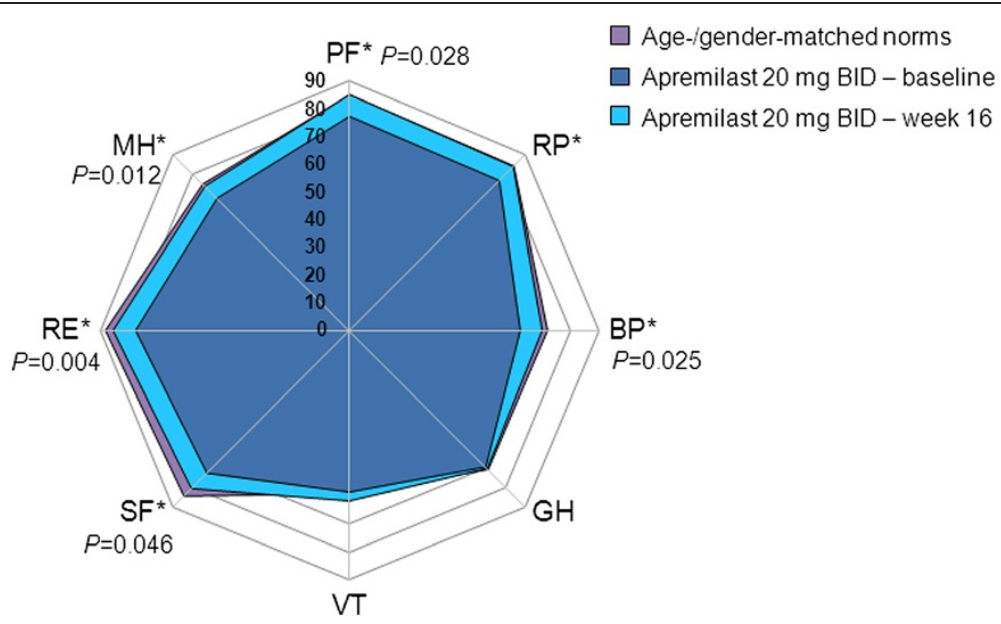

Figure 3 SF-36 domain scores at baseline and week 16 with apremilast 20 mg BID. Spydergram of SF-36 domain scores in patients receiving apremilast $20 \mathrm{mg}$ BID versus US age-/gender-matched norms (lavender) and baseline (dark blue). Gridlines represent changes of 10 points each (10 points $=2 \times$ MCID). An increase in score indicates improvement. Treatment-associated improvements (light blue) are statistically significant in five and $\geq$ MCID in six of eight domains. MCID, minimal clinically important difference; SF-36, 36-item Short-Form Health Survey. ${ }^{*} \geq$ MCID.

moderate overall and statistically significant $(P<0.02)$; correlations between VT domain and MCS scores and pruritus VAS were low, and statistically significant with apremilast $30 \mathrm{mg}$ BID only.

\section{Discussion}

In this RCT, patients with moderate to severe plaque psoriasis reported impairments in disease-specific and generic measures of HRQOL at baseline, evidenced by mean DLQI scores $>10$ and SF-36 MCS scores 0.5 SDs below US age-/gender-matched norms. Statistically significant and clinically meaningful improvements in SF-36 MCS and domain scores were reported by patients treated with apremilast, most evident in the 20and 30-mg BID dose groups, mirrored by decreases in disease-specific DLQI and pruritus VAS scores. In contrast, patients receiving placebo reported little change or deterioration from baseline in HRQOL. Correlations between SF-36 MCS, BP, and VT scores and DLQI were moderate and, in general, statistically significant. Correlations between SF-36 scores and pruritus VAS were moderate to low, indicating that they measure different

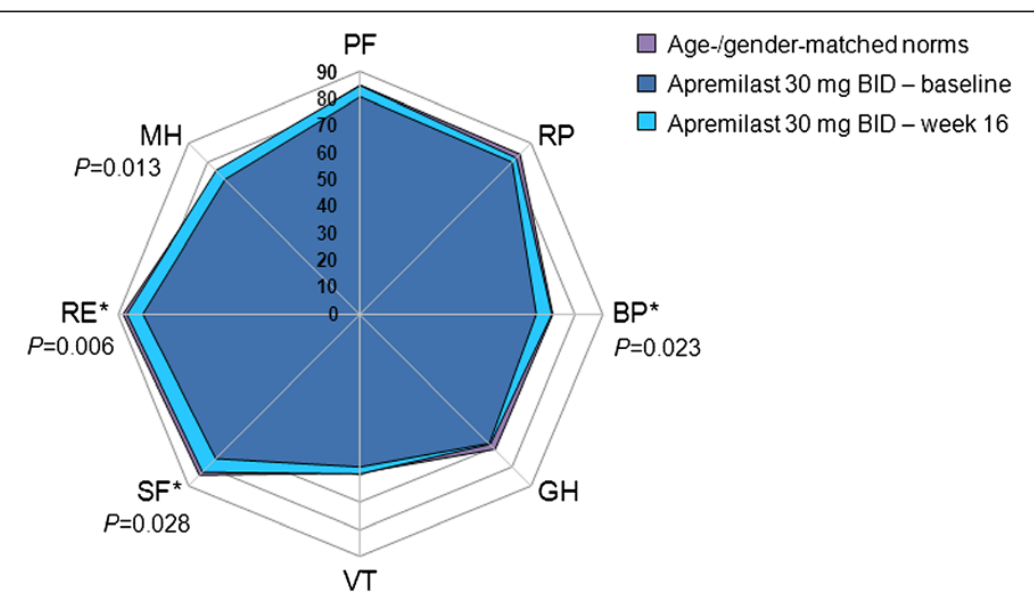

Figure 4 SF-36 domain scores at baseline and week 16 with apremilast 30 mg BID. Spydergram of SF-36 domain scores in patients receiving apremilast $30 \mathrm{mg}$ BID versus US age-/gender-matched norms (lavender) and baseline (dark blue). Gridlines represent changes of 10 points each (10 = 2x MCID of 5 points). An increase in score indicates improvement. Treatment associated improvements (light blue) are statistically significant in four of eight domains and $\geq M C I D$ in three of eight domains. MCID, minimal clinically important difference; SF-36, 36item Short-Form Health Survey. $\geq$ MCID. 
Table 4 Correlations of changes in SF-36 BP, VT, and MCS scores with changes in DLQI and pruritus VAS scores at week 16

\begin{tabular}{lcccc}
\hline & Placebo & \multicolumn{3}{c}{ Apremilast BID } \\
\cline { 3 - 5 } & & $\mathbf{1 0} \mathbf{~ m g}$ & $\mathbf{2 0} \mathbf{~ m g}$ & $\mathbf{3 0} \mathbf{~ m g}$ \\
\hline SF-36 BP with DLQI & $-0.45^{*}$ & $-0.32^{*}$ & $-0.52^{*}$ & $-0.35^{*}$ \\
& $P<0.001$ & $P=0.002$ & $P<0.001$ & $P=0.001$ \\
SF-36 VT with DLQI & $0.38^{*}$ & -0.18 & $-0.33^{*}$ & -0.23 \\
& $P<0.001$ & $P=N S$ & $P=0.003$ & $P=0.040$ \\
SF-36 MCS with DLQI & $-0.57^{*}$ & $-0.41^{*}$ & $-0.42^{*}$ & $-0.31^{*}$ \\
SF-36 BP with pruritus VAS & $P<0.001$ & $P<0.001$ & $P<0.001$ & $P=0.004$ \\
& $-0.39^{*}$ & -0.27 & $-0.43^{*}$ & -0.30 \\
SF-36 VT with pruritus VAS & $P<0.001$ & $P=0.013$ & $P<0.001$ & $P=0.005$ \\
& $-0.36^{*}$ & 0.01 & -0.11 & -0.23 \\
SF-36 MCS with pruritus VAS & $P=0.001$ & $P=N S$ & $P=N S$ & $P=0.034$ \\
& $-0.35^{*}$ & -0.21 & -0.12 & $-0.35^{*}$ \\
& $P=0.001$ & $P=N S$ & $P=N S$ & $P=0.001$ \\
\hline
\end{tabular}

*Moderate correlations $(r>0.30$ and $\leq 0.60)$

BP, Bodily Pain; DLQI, Dermatology Life Quality Index; MCS, mental component summary; SF-36, Short-Form 36 Health Survey; VAS, visual analog scale; VT, Vitality.

impacts of the disease and highlighting the value in assessing efficacy using multiple instruments.

\section{Interpretation and implications}

Growing evidence clearly shows that impairments in HRQOL are a large component of the disease burden imposed by psoriasis. These results are in line with national survey findings that show the majority of individuals with psoriasis experience emotional as well as physical disease-related problems [34]. In that survey, $63 \%$ of respondents reported that psoriasis impacts their emotional well-being, marked by feelings of helplessness, anger, embarrassment, and frustration. Given the generally high level of emotional distress patients report regarding psoriasis symptoms, it is important to describe the potential impact of treatment on emotional functioning. Emotional distress has been linked to onset of psoriasis flares, more severe symptoms, and presence of lesions in visible locations $[3,35]$ and may contribute to heightened risk of major depressive disorder, often seen in this patient population $[5,6,36]$. This trial contributes to other RCT data demonstrating that efficacious treatment of moderate to severe psoriasis results in improvements in HRQOL [7-9,37,38]. Consistent with findings from other studies [7], psoriasis appears to have relatively greater impact on mental health rather than physical domains, as patients report larger decrements in $\mathrm{RE}$ and SF and to a lesser degree BP domains. This suggests that the impact of physical well-being on mental health might well depend on the nature of the physical impairment, as skin disease may have a disproportionately large effect on mental functioning and ensuing HRQOL whereas joint disease in PsA has more impact on PF, BP, and VT domains. These data demonstrate moderate correlations between improvements in disease-specific functioning, based on DLQI, and broader improvements in SF-36 MCS scores and BP, SF, and RE domains. This likely reflects improvements in painful psoriatic plaques and/or joint pain associated with comorbid PsA, although only a minority of patients reported the presence of arthritis. The ability to measure treatment efficacy based on broader generic instruments has implications when considering comparisons with normative populations as well as across disease states. Disease-associated decrements in HRQOL reported by patients with psoriasis indicate that a multipronged approach could enhance assessment of treatment effectiveness. This approach should encompass clinical signs and symptoms, as well as patient-reported HRQOL, using both disease-specific and generic instruments.

\section{Apremilast clinical data}

As described in a separate report [20], the primary results of this study demonstrate the efficacy and tolerability of apremilast 20 and $30 \mathrm{mg}$ BID over 24 weeks in patients with moderate to severe plaque psoriasis, including significant improvements in PASI, pruritus, static Physician's Global Assessment, and BSA scores. The most frequently reported adverse events were headache, nausea, vomiting, nasopharyngitis, and upper respiratory tract infection. The majority of adverse events $(>96 \%)$ were mild or moderate in severity, and rates of discontinuations due to adverse events were generally low $(\approx 10 \%)$. Gastrointestinal events were generally transient. Importantly, no opportunistic infections were reported, and no serious infections were considered related to apremilast [20].

The tolerability findings are important in their relationship to the improved HRQOL seen in this study. While improvement in the severity of disease can be expected in most cases to improve HRQOL, there are some instances in which tolerability and safety issues may abrogate this benefit. The results of the current analysis indicate that this was not the case with apremilast. While the most commonly reported adverse events were related to gastrointestinal complaints and headache, this did not appear to outweigh the benefit of therapy, and resulted in an overall improvement in HRQOL.

On the basis of phase II findings, further examination of the efficacy and safety of apremilast for the treatment of psoriasis is underway in phase III studies. The ESTEEM (Efficacy and Safety Trial Evaluating the Effects of apreMilast in psoriasis) clinical trial program includes two 52-week RCTs, each with a 16-week placebo- 
controlled phase, randomized withdrawal phase for PASI responders, and long-term, open-label extension to assess the efficacy, tolerability, and effects of apremilast on HRQOL in patients with moderate to severe plaque psoriasis. Recently, topline results from the ESTEEM 1 trial were presented [39]. At week 16, a significantly greater proportion of patients receiving apremilast 30 mg BID achieved PASI-75 (33.1\%) and PASI-50 (58.7\%) compared with placebo (5.3\% and $17.0 \%$; $P<0.0001$ for both). Apremilast was also associated with significant improvements in static Physician's Global Assessment, pruritus VAS, and DLQI as well as difficult-to-treat nail and scalp psoriasis. Apremilast was well-tolerated and no new safety or laboratory signals were detected. Additional results are anticipated. In addition, apremilast is currently being investigated in phase III clinical trials for the treatment of PsA and ankylosing spondylitis.

\section{Limitations}

The study enrolled patients with moderate to severe plaque psoriasis and results may not be applicable to patients with other forms of psoriasis. This report is based on PROs after 16 weeks of treatment, although a separate publication indicates that improvements with active therapy are generally maintained over 24 weeks of treatment [20]. Ongoing phase III studies are expected to yield valuable information.

\section{Conclusions}

Moderate to severe plaque psoriasis is associated with a negative impact on HRQOL, including pain and social and emotional functioning. Assessment of clinical signs and symptoms, as well as PROs, is useful in determining the impact of psoriasis and the clinical efficacy of treatment. In this study, apremilast $20 \mathrm{mg}$ and $30 \mathrm{mg}$ BID consistently resulted in statistically significant and clinically meaningful improvements in disease-specific and generic measures of HRQOL in patients with longstanding, moderate to severe plaque psoriasis. Findings indicate that the benefit:risk profile of apremilast results in a net improvement in HRQOL for the patient.

\footnotetext{
Abbreviations

BP: Bodily Pain [cap p]; BSA: Body surface area; cAMP: Cyclic adenosine monophosphate; DLQI: Dermatology Life Quality Index; HRQOL: Healthrelated quality of life; LOCF: Last observation carried forward;

MCID: Minimum clinically important differences; MCS: Mental component summary; PASI-75: $\geq 75 \%$ mean reductions from baseline in Psoriasis Area and Severity Index; PDE4: Phosphodiesterase 4; PCS: Physical component summary; PF: Physical Functioning; PROs: Patient-reported outcomes; PsA: Psoriatic arthritis; RCT: Randomized, controlled trial; RE: Role-Emotional; SDs: Standard deviations; SF: Social Functioning; SF-36: 36-item Short-Form Health Survey; VAS: Visual analog scale; VT: Vitality.
}

\section{Competing interests}

VS has been a consultant to and member of scientific advisory boards for Abbott Immunology, Alder Biopharmaceuticals, Amgen, Biogenldec, BMS, Celgene Corporation, Galderma, Idera, Incyte, Janssen, Medlmmune, Novartis,
Pfizer Inc, Regeneron, Rigel, Roche, Sanofi, and UCB. DF has served as an investigator for Amgen, Celgene Corporation, Janssen, Pfizer Inc, and Roche, and as a paid advisor for Amgen, Janssen, Medlmmune, and Rigel. CH, RMD, and RMS are employees of Celgene Corporation. KAP has served as an investigator for Abbott, Amgen, Boehringer Ingelheim, BMS, Celgene Corporation, Centocor, Galderma, Isotechnika, Janssen, Leo Pharma, Lilly, Medlmmune, Merck, Novartis, and Pfizer Inc; an adviser for Abbott, Amgen, Astellas, BMS, Celgene Corporation, Centocor, Galderma, Incyte, Isotechnika, Janssen, Johnson \& Johnson, Lilly, Medlmmune, Merck, Novartis, Pfizer Inc, and UCB; and a speaker for Abbott, Amgen, Astellas, Celgene Corporation, Centocor, Isotechnika, Janssen, Novartis, and Pfizer Inc.

\section{Authors' contributions}

All authors had full access to all of the data in the study. VS, DF, CH, RMD, RMS, KAP: Conceived of the study, participated in the design and coordination of the study, and helped to draft the manuscript. CH, RMD, RMS, KAP: Supervised on and performed data analyses and helped to draft the manuscript. VS, CH, RMD, RMS, KAP: Analyzed and interpreted the data and helped to draft the manuscript. VS, DF, CH, RMD, RMS, KAP: All authors had full access to the data and have read and approved the final manuscript.

\section{Acknowledgements}

This study was sponsored by Celgene Corporation. The authors received editorial support in the preparation of this manuscript from Peloton Advantage, LLC, and Jennifer Schwinn, RPh, funded by Celgene Corporation. The authors, however, directed and are fully responsible for all content and editorial decisions for this manuscript.

\section{Author details}

'Division of Immunology and Rheumatology, Stanford University, Palo Alto, California, USA. ${ }^{2}$ Department of Dermatology, Stanford University School of Medicine, Redwood City, California, USA. ${ }^{3}$ Celgene Corporation, Summit, New Jersey, USA. ${ }^{4}$ Probity Medical Research, Waterloo, Ontario, Canada.

Received: 21 December 2012 Accepted: 7 May 2013

Published: 10 May 2013

\section{References}

1. Kurd SK, Gelfand JM: The prevalence of previously diagnosed and undiagnosed psoriasis in US adults: results from NHANES 2003-2004. J Am Acad Dermatol 2009, 60:218-224.

2. Augustin M, Reich K, Glaeske G, Schaefer I, Radtke M: Co-morbidity and age-related prevalence of psoriasis: analysis of health insurance data in Germany. Acta Derm Venereol 2010, 90:147-151.

3. Kimball AB, Jacobson C, Weiss S, Vreeland MG, Wu Y: The psychosocial burden of psoriasis. Am J Clin Dermatol 2005, 6:383-392.

4. Reich A, Hrehorow E, Szepietowski JC: Pruritus is an important factor negatively influencing the well-being of psoriatic patients. Acta Derm Venereol 2010, 90:257-263.

5. Meyer N, Paul C, Feneron D, Bardoulat I, Thiriet C, Camara C, Sid-Mohand D, Le Pen C, Ortonne JP: Psoriasis: an epidemiological evaluation of disease burden in 590 patients. J Eur Acad Dermatol Venereol 2010, 24:1075-1082.

6. Kurd SK, Troxel AB, Crits-Christoph P, Gelfand JM: The risk of depression, anxiety, and suicidality in patients with psoriasis: a population-based cohort study. Arch Dermatol 2010, 146:891-895.

7. Strand V, Sharp V, Koenig AS, Park G, Shi Y, Wang B, Zack DJ, Fiorentino D: Comparison of health-related quality of life in rheumatoid arthritis, psoriatic arthritis and psoriasis and effects of etanercept treatment. Ann Rheum Dis 2012, 17:1143-1150.

8. Krueger GG, Langley RG, Finlay AY, Griffiths CE, Woolley JM, Lalla D, Jahreis A: Patient-reported outcomes of psoriasis improvement with etanercept therapy: results of a randomized phase III trial. Br J Dermatol 2005, 153:1192-1199.

9. Lebwohl M, Papp K, Han C, Schenkel B, Yeilding N, Wang Y, Krueger GG: Ustekinumab improves health-related quality of life in patients with moderate-to-severe psoriasis: results from the PHOENIX 1 trial. Br J Dermatol 2010, 162:137-146.

10. Reich K, Nestle FO, Papp K, Ortonne JP, Evans R, Guzzo C, Li S, Dooley LT, Griffiths CE: Infliximab induction and maintenance therapy for moderate- 
to-severe psoriasis: a phase III, multicentre, double-blind trial. Lancet 2005, 366:1367-1374.

11. Saurat JH, Guerin A, Yu AP, Latremouille-Viau D, Wu EQ, Gupta SR, Bao Y, Mulani PM: High prevalence of potential drug-drug interactions for psoriasis patients prescribed methotrexate or cyclosporine for psoriasis: associated clinical and economic outcomes in real-world practice. Dermatology 2010, 220:128-137.

12. Ravindran V, Scott DL, Choy EH: A systematic review and meta-analysis of efficacy and toxicity of disease modifying anti-rheumatic drugs and biological agents for psoriatic arthritis. Ann Rheum Dis 2008, 67:855-859.

13. Richards HL, Fortune DG, Griffiths CE: Adherence to treatment in patients with psoriasis. J Eur Acad Dermatol Venereol 2006, 20:370-379.

14. Serezani $\mathrm{CH}$, Ballinger MN, Aronoff DM, Peters-Golden M: Cyclic AMP: master regulator of innate immune cell function. Am J Respir Cell Mol Biol 2008, 39:127-132

15. Tasken K, Aandahl EM: Localized effects of cAMP mediated by distinct routes of protein kinase A. Physiol Rev 2004, 84:137-167.

16. Houslay MD, Schafer $P$, Zhang KY: Keynote review: phosphodiesterase- 4 as a therapeutic target. Drug Discov Today 2005, 10:1503-1519.

17. Baumer W, Hoppmann J, Rundfeldt C, Kietzmann M: Highly selective phosphodiesterase 4 inhibitors for the treatment of allergic skin diseases and psoriasis. Inflamm Allergy Drug Targets 2007, 6:17-26

18. Schafer PH, Parton A, Gandhi AK, Capone L, Adams M, Wu L, Bartlett JB, Loveland MA, Gilhar A, Cheung Y-F, Baillie GS, Houslay MD, Man H-W, Muller GW, Stirling DI: Apremilast, a cAMP phosphodiesterase-4 inhibitor, demonstrates anti-inflammatory activity in vitro and in a model of psoriasis. Br J Pharmacol 2010, 159:842-855

19. Salari $P$, Abdollahi $M$ : Phosphodiesterase inhibitors in inflammatory bowel disease. Expert Opin Investig Drugs 2012, 21:261-264

20. Papp K, Cather J, Rosoph L, Sofen H, Langley RG, Matheson RT, Hu A, Day $\mathrm{RM}$ : The efficacy of apremilast, a phosphodiesterase- 4 inhibitor, in the treatment of moderate to severe psoriasis: results of a phase 2 randomised study. Lancet 2012, 380:738-746.

21. Schett G, Wollenhaupt J, Papp K, Joos R, DeVlam KL, Rodrigues JF, Vessey A, Hu CC, Stevens R: Oral apremilast in the treatment of active psoriatic arthritis: results of a multicenter, randomized, double-blind, placebocontrolled study. Arthritis Rheum 2012, 64:3156-3167.

22. Gottlieb AB, Strober B, Krueger JG, Rohane P, Zeldis JB, Hu CC, Kipnis C: An open-label, single-arm pilot study in patients with severe plaque-type psoriasis treated with an oral anti-inflammatory agent, apremilast. Curr Med Res Opin 2008, 24:1529-1538.

23. Basra MK, Fenech R, Gatt RM, Salek MS, Finlay AY: The Dermatology Life Quality Index 1994-2007: a comprehensive review of validation data and clinical results. Br J Dermatol 2008, 159:997-1035.

24. Strand V, Bombardier C, Maetzel A, Scott D, Crawford B: Use of minimum clinically important differences (MCID) in evaluating patient responses to treatment of rheumatoid arthtitis (RA) [abstract 810]. Arthritis Rheum 2001, 44(suppl 9):S187

25. Strand V, Scott DL, Emery P, Kalden JR, Smolen JS, Cannon GW, Tugwell P, Crawford B: Physical function and health related quality of life: analysis of 2-year data from randomized, controlled studies of leflunomide, sulfasalazine, or methotrexate in patients with active rheumatoid arthritis. J Rheumatol 2005, 32:590-601.

26. Hazes JM, Taylor P, Strand V, Purcaru O, Coteur G, Mease P: Physical function improvements and relief from fatigue and pain are associated with increased productivity at work and at home in rheumatoid arthritis patients treated with certolizumab pegol. Rheumatology (Oxford) 2010 49:1900-1910.

27. Tugwell P, Wells G, Strand V, Maetzel A, Bombardier C, Crawford B, Dorrier C, Thompson A: Clinical improvement as reflected in measures of function and health-related quality of life following treatment with leflunomide compared with methotrexate in patients with rheumatoid arthritis: sensitivity and relative efficiency to detect a treatment effect in a twelve-month, placebo-controlled trial. Leflunomide Rheumatoid Arthritis Investigators Group. Arthritis Rheum 2000, 43:506-514

28. Hongbo $Y$, Thomas $C L$, Harrison MA, Salek MS, Finlay AY: Translating the science of quality of life into practice: What do dermatology life quality index scores mean? J Invest Dermatol 2005, 125:659-664.

29. Strand V, Crawford B, Singh J, Choy E, Smolen JS, Khanna D: Use of "spydergrams" to present and interpret SF-36 health-related quality of life data across rheumatic diseases. Ann Rheum Dis 2009, 68:1800-1804.
30. Ara R, Brazier J: Deriving an algorithm to convert the eight mean SF-36 dimension scores into a mean EQ-5D preference-based score from published studies (where patient level data are not available). Value Health 2008, 11:1131-1143.

31. Ara R, Brazier J: Predicting the short form-6D preference-based index using the eight mean short form-36 health dimension scores: estimating preference-based health-related utilities when patient level data are not available. Value Health 2009, 12:346-353.

32. Ware J, Kosinski M, Dewey JE: How to Score Version 2 of the SF-36 Health Survey. Lincoln, Rl: QualityMetric Inc.; 2000.

33. Cohen J: Statistical Power Analysis for the Behavioral Sciences. 2nd edition. Hillsdale, NJ: Lawrence Erlbaum Associates, Inc.; 1988

34. National Psoriasis Foundation: Report on the Psycho-Social Impacts of Psoriasis. [www.psoriasis.org/Document.DOC?id=619]

35. Devrimci-Ozguven $H$, Kundakci TN, Kumbasar $H$, Boyvat A: The depression, anxiety, life satisfaction and affective expression levels in psoriasis patients. J Eur Acad Dermatol Venereol 2000, 14:267-271.

36. Kimball AB, Gladman D, Gelfand JM, Gordon K, Horn EJ, Korman NJ, Korver G, Krueger GG, Strober BE, Lebwohl MG: National Psoriasis Foundation clinical consensus on psoriasis comorbidities and recommendations for screening. J Am Acad Dermatol 2008, 58:1031-1042.

37. Kimball AB, Bensimon AG, Guerin A, Yu AP, Wu EQ, Okun MM, Bao Y, Gupta SR, Mulani PM: Efficacy and safety of adalimumab among patients with moderate to severe psoriasis with co-morbidities: Subanalysis of results from a randomized, double-blind, placebo-controlled, phase III trial. Am J Clin Dermatol 2011, 12:51-62.

38. Flytstrom I, Stenberg B, Svensson A, Bergbrant IM: Methotrexate vs. ciclosporin in psoriasis: effectiveness, quality of life and safety. A randomized controlled trial. $\mathrm{Br} J$ Dermatol 2008, 158:116-121.

39. Reich K: Apremilast, an oral phosphodiesterase 4 inhibitor, in patients with moderate to severe psoriasis: 16-week results of a phase 3, randomized, controlled trial (ESTEEM 1) [oral presentation]. Miami, FL: Presented at: the 71st Annual Meeting of the American Academy of Dermatology; 2013.

\section{doi:10.1186/1477-7525-11-82}

Cite this article as: Strand et al:: Improvements in patient-reported outcomes with apremilast, an oral phosphodiesterase 4 inhibitor, in the treatment of moderate to severe psoriasis: results from a phase Ilb randomized, controlled study. Health and Quality of Life Outcomes 2013 11:82.

\section{Submit your next manuscript to BioMed Central and take full advantage of:}

- Convenient online submission

- Thorough peer review

- No space constraints or color figure charges

- Immediate publication on acceptance

- Inclusion in PubMed, CAS, Scopus and Google Scholar

- Research which is freely available for redistribution 